\title{
Bundesrat Mumentaler
}

Der Herr Bundesrat vertritt kompromisslos die harte Linie seiner Partei: absolute Drogenprohibition und Strafen für jeden Cannabiskonsumenten. Doch persönlich steht es nicht gut um ihn, denn die Ehefrau will sich scheiden lassen, die Parteipräsidentin intrigiert gegen seine Wiederwahl und sein Augenarzt diagnostiziert einen grünen Star. Weil er die üblichen Medikamente nicht erträgt, empfiehlt ihm dieser Cannabis und das Heil (oder Unheil) nimmt seinen Lauf.

Wie war das im realen Politleben der Schweiz? Da ging es doch einmal darum, das Betäubungsmittelgesetz aus dem Jahre 1951 zu revidieren. Der Bundesrat hatte dazu eine Expertenkommission einberufen, die nach sorgfältiger Prüfung aller Risiken die Freigabe des Hanfkonsums empfahl. Im Oktober 2000 sprach sich die Landesregierung dafür aus, Konsum, Erwerb, Besitz und Eigenanbau nicht weiter zu bestrafen. Ständerat und Nationalrat hatten im gleichen Jahr entschieden, die Cannabislegalisierung zu behandeln, und eine Studie der Fachstelle für Alkoholund andere Drogenprobleme (SFA) stellte fest, dass sich 53\% der Bevölkerung für eine Legalisierung aussprachen. Zweimal hatte der Ständerat zu einer Revision klar ja gesagt, dann verhinderte der Nationalrat im Juni 2004, mit 102 zu 92 Stimmen, genau diese Revision des Betäubungsmittelgesetzes. Vergeblich war der ärztliche Aufruf von Cavalli an die Ratskollegen, ihre Angstzustände und ihre Paranoia zu überwinden. Seither herrscht die drogenpolitische Eiszeit, eingeschlossen jegliche Form medizinischer Anwendungen.

Bundesrat Mumentaler lernt einen jungen Kiffer namens Remo kennen und bald auch schätzen. Er löffelt das Kraut mit Yoghurt, knabbert es im Süssgebäck und raucht es schliesslich mit Hilfe seines schlitzohrigen Freundes. Mit dem Augeninnendruck ändert sich umfassend das Gemüt des Magistraten. Er wird locker und gemütlich, witzig und sympathisch. Er mutiert zum Liebling der Presse, skatet durch die Berner Innenstadt und fördert das Liebesleben seines schüchternen Dealers. Die wundersame Verwandlung macht ihn zum engagierten Befürworter der Legalisierung. Am Ende seiner Amtszeit überzeugt er das Parlament und verliert die Wiederwahl. Dafür spielt er im Jazzkeller Trompete, und die Gattin haucht ihm einen Kuss zu. Ende der Geschichte.
Das letztmals 1975 revidierte Betäubungsmittelgesetz ist ein Gesetz nach amerikanischem Vorbild. Seit 1925 betreiben die USA aus vielfältigen Motiven eine restriktive und repressive Cannabispolitik. Von dieser radikalen Prohibitionsideologie wird auch die UN-Konvention von 1988 bestimmt. Wer als Signatarstaat von dieser Praxis abweicht, riskiert einen Konflikt mit dem Kontrollrat der Vereinten Nationen, sprich mit den USA. Obwohl die Drogenrepression mehr kostet, als sie bringt, diktiert das verordnete Wunschdenken als globales Ziel eine drogenfreie Welt bis 2008. Unwiderstehlich ist die Versuchung, mit einer undifferenzierten Drogenpolitik Stimmen zu holen. Zudem hatte der Drogenkrieg von Anfang an viele militärische und geheimdienstliche Nutzniesser, die ihn unbehindert für ihre eigenen Geschäfte missbrauchen. Doch einem Handel, der inzwischen rund acht Prozent des Welthandelsvolumens ausmacht, ist mit Repression nicht beizukommen. Der Schweizer Historiker Jakob Tanner schreibt den verkappten Moralkampagnen eine gesellschaftliche Stabilisierungs- und Orientierungsfunktion in kulturellen Krisenlagen zu. Schliesslich leben auch viele Berufe von der geschürten Hysterie.

Zugegeben, die Kifferkomödie «Cannabis» ist ein leichter Stoff. Im Drehbuch, das der Regisseur Niklaus Hilber mit dem Theaterautor Paul Steinmann verfasst hat, wimmelt es von Klischees. Dass der Film trotzdem unterhaltend ist, liegt an den schauspielerischen Leistungen von Hanspeter Müller-Drossaart und Joel Basman. Mit Witz und Charme spielen sie das Märchen von der kiffenden Leichtigkeit des Seins. Vermutlich wirken Humor und Romantik in politischen Eiszeiten besser als Detailtreue und Sachargumente. Eine Schwalbe macht noch keinen Frühling, aber vielleicht findet das Thema freche und subversive Nachahmer. Das kann noch dauern. Darum warten wir geduldig, bis sich hierzulande wider Erwarten etwas bewegt. Au revoir, Monsieur Mumentaler!

Erhard Taverna

- Cannabis. Filmkomödie. Regie: Niklaus Hilber. Schweiz; 2006. Ca. 82 Minuten. 